\title{
A First Principles Study of the Distribution of Iron in
}

\section{Sphalerite.}

\author{
Kate Wright and Julian D. Gale
}

Nanochemistry Research Institute, Department of Chemistry, Curtin University of Technology, GPO Box U1987, Perth, WA 6845, Australia.

Submitted to:

Date of submission:

Date of Revision:

Keywords:
Geochimica and Cosmochimica Acta

$29^{\text {th }}$ October 2009

$22^{\text {nd }}$ February 2010

Sphalerite, Iron Substitution, Density Functional Theory 


\begin{abstract}
.
Quantum mechanical techniques, based on density functional theory, have been used to study the distribution of iron impurities in sphalerite $(\mathrm{ZnS})$ at compositions ranging from 3.125 to $12.5 \mathrm{~mol} \% \mathrm{FeS}$. Our results show that iron is most easily incorporated by direct substitution onto the zinc site and that energies for solution reactions involving FeS are exothermic when the system is zinc deficient. Furthermore, there appears to be a small driving force for the formation of bound $\mathrm{Fe}-\mathrm{Fe}$ pairs at low iron concentrations, though there is no particular preference found for larger clusters of iron. The influence of iron on the sphalerite cell parameter is shown to be sensitive to the presence of Fe-Fe pairs and to the degree of sample non-stoichiometry.
\end{abstract}




\section{INTRODUCTION}

Sphalerite, the cubic form of $\mathrm{ZnS}$, is the principal ore of zinc and thus of economic importance. It is also of interest because of its semiconducting properties, particularly since its band gap is in a region that lends itself to technological applications (Cao et al 2004). Pure sphalerite is rarely found in nature, but usually contains significant amounts of $\mathrm{Cd}$ (up to $15 \mathrm{~mol} \%$, though typically much lower) and $\mathrm{Mn}$ (up to $4 \%$ ) substituting for $\mathrm{Zn}$, as well as small amounts of $\mathrm{Ga}, \mathrm{Ge}$, In, Co and $\mathrm{Hg}$, amongst other elements (Cook et al 2009). However, the most common impurity is Fe, which is generally present at levels of up to $26 \mathrm{~mol} \%$, although compositions of up to 56 mol\% have been reported (Pattrick et al. 1998; Di Bendetto et al 2005b). There is considerable evidence to suggest that the Fe content of sphalerite is related to pressure when it is in equilibrium with $\mathrm{FeS}$ and $\mathrm{FeS}_{2}$ (e.g. Barton and Toulmin 1966; Scott and Barnes 1971), and has been used as both a geo- and cosmo-baromater (Balabin and Urusov 1995), although not without some controversy (Toulmin et al 1991).

The distribution of $\mathrm{Fe}$ and other impurities within the sphalerite crystal lattice is variable, with some samples showing compositional zoning over length scales ranging from sub-micron to centimetres. It is generally believed that this compositional zoning is a growth phenomenon, controlled in part by competition between $\mathrm{Zn}$ and other cations for surface sites (Di Benedetto et al 2005a). Differences in Fe zoning behaviour have also been observed depending on the presence or absence of $\mathrm{Mn}$ (Pattrick et al 1998; Di Benedetto et al 2005a). Additional factors that influence the uptake of $\mathrm{Fe}$ by sphalerite include temperature and sulphur fugacity, with high sulphur fugacity being linked to increased $\mathrm{Fe}^{3+}$ charge compensation for $\mathrm{Zn}$ vacancies. Recent studies of Mn (Bernardini et al 2004) and Fe distribution (Lepetit et 
al 2003, Di Benedetto et al 2005b) in sphalerite using EPR and Mössbauer spectroscopy, respectively, both point towards the formation of impurity pairs and of clustering by the impurities at the nanoscale. This is supported by calculations using the Cluster Variation Method (CVM) (Balabin and Sack 2000). However, other studies using electron diffraction coupled with Monte Carlo simulations (Withers et al 2005) find no evidence for iron clustering.

Although there has been considerable success in determining the influence of impurities on the structure and properties of sphalerite, and in mapping of their distribution within individual grains, considerable gaps are apparent in our understanding of the crystal chemical controls on impurity incorporation at the atomic level. In the current study, we use first principles calculations, based on Density Functional Theory (DFT), to investigate the details of the Fe uptake and distribution in sphalerite. 


\section{THEORETICAL METHODS}

All calculations have been performed within the framework of non-local density functional theory using the PBE generalized gradient approximation (GGA) of Perdew et al (1996). The numerical solution of the Kohn-Sham equations was obtained through use of the SIESTA methodology and software (Soler et al 2002). Here the core electrons and nuclei are represented by non-local pseudopotentials of the Kleinmann-Bylander form, and the construction was performed according to the modified scheme of Troullier and Martins (Troullier and Martins 1991) with inclusion of relativistic effects. Small core pseudopotentials were selected for the metals, with the valence electronic configurations used in the pseudopotential generation being $\mathrm{Zn}$ $\left(3 d^{10}, 4 s^{1}\right), S\left(3 s^{2}, 3 p^{3.5}, 3 d^{0.5}\right)$ and $F e\left(3 p^{6}, 4 s^{2}, 3 d^{6}\right)$. For $\mathrm{Zn}$ and Fe, partial core corrections (Louie et al 1982) were also included to ensure a high degree of reproduction of the all-electron results for electron promotion and ionization processes.

The valence electron wavefunctions are expanded as a linear combination of strictly localized pseudo-atomic orbitals (i.e. these are numerical tabulations of the solutions of the pseudised atomic problem within a confinement potential). In the present work, the soft confinement scheme of Junquera et al (2001) has been employed to avoid the discontinuity in the basis function first derivative at the radial cut-off. The basis set employed was of double-zeta plus polarization quality for sulphur, and double-zeta for $\mathrm{Fe}$ and $\mathrm{Zn}$ (i.e. no f functions were included) except for the $4 \mathrm{p}$ orbitals, which are formally unoccupied, where only a single-zeta was found to be required. Again, following the work of Junquera et al, (2001), the confinement and orbital parameters were variationally optimized for relevant reference systems. For $\mathrm{Zn}$ and $\mathrm{S}$, the 
parameters were optimized with respect to zinc sulphide in the sphalerite phase, while those for Fe were determined for the pyrite and marcasite phases of $\mathrm{FeS}_{2}$. Although the local coordination environment in $\mathrm{FeS}_{2}$ polymorphs is different from the present material, the lower symmetries of these structures are more appropriate for the variational optimisation of the basis set parameters and provide a more stringent test of quality than a high symmetry material.

The evaluation of the Hartree and exchange-correlation potentials was conducted on an auxiliary basis set consisting of a uniform real-space grid with an equivalent kinetic energy cut-off of 580 Ry. Brillouin zone integration was performed according to the Monkhorst-Pack scheme with grid dimensions corresponding to an equivalent real-space cut-off of $12 \AA$ (Moreno and Soler 1992). Finally, all calculations where iron is present include spin polarization with the total spin being allowed to vary such that the Fermi energy is the same for all electrons.

All geometry optimizations were performed using conjugate gradients with a force convergence criterion of $0.01 \mathrm{eV} / \AA$ and a stress tolerance of 200 bar. No symmetry constraints were applied to either the nuclear or electronic degrees of freedom. Phonon calculations were performed through the use of central finite differences about the optimized structure to determine the force constant matrix using a step size of 0.04 Bohr and isotopically averaged masses of 55.85, 65.38 and 32.06 a.u. for Fe, Zn and S, respectively.

\subsection{Treatment of Defects}

The majority of defect calculations were performed using a $2 \times 2 \times 2$ supercell of sphalerite, containing 32 formula units, which was sufficient to converge the energy of a single iron impurity to better than $0.01 \mathrm{eV}$ (i.e. of the same order as ambient 
thermal energy) with respect to larger supercells. Iron dopants are introduced into the supercell as bound clusters, unbound clusters and isolated impurities, as illustrated in Figures 1 and 2. Solution reactions between sphalerite and iron, described below, have been determined with respect to $\mathrm{FeS}$ in the troilite phase.

The incorporation of Fe into a 64-atom supercell, with no other defects present, is described by:

$$
32(Z n S)+n F e S \Rightarrow\left(F e_{n} Z n_{32-n} S_{32}\right)+n Z n S
$$

The solution energy $\left(E_{S o l}\right)$ is computed by summing the energies of the individual components as:

$$
E_{\text {Sol }}=\left(E_{\text {Def }}+E_{n Z n S}\right)-\left(E_{\text {Pure }}+E_{n F e S}\right)
$$

Here, $E_{D e f}$ and $E_{\text {Pure }}$ are the energies of the defective and pure supercells, respectively, and $E_{n Z n S}$ and $E_{n F e S}$ are the energies of $n$ units of $\mathrm{ZnS}$ and FeS used in the reaction. We have performed calculations on supercells for $n=1,2,3$ and 4 where the individual Fe atoms are either isolated from each other, in pairs, in larger clusters, or bound to zinc vacancies. For this latter case, the solution reaction becomes;

$$
\left(Z n_{31} S_{32}\right)+n F e S \Rightarrow\left(F e_{n} Z n_{31-n} S_{32}\right)+n Z n S
$$

where the supercell containing the zinc vacancy equates to a formula of $\mathrm{Zn}_{1-\mathrm{x}} \mathrm{S}$, with $\mathrm{x}$ $=0.03215$. 


\section{RESULTS AND DISCUSSION}

\subsection{Pure Phases}

Sphalerite has a cubic unit cell with space group F-43M containing 8 atoms, all of which are in tetrahedral coordination. The calculated cell parameter is $5.458 \AA, 1 \%$ larger than the experimental value of $5.405 \AA$, as is to be expected based on the systematic overestimation typically observed for the present GGA functional. In a previous study of sphalerite (von Oertzen et al 2005), cell parameters of 5.412 and $5.426 \AA$ were obtained for the same functional, when using plane-wave and Gaussian basis sets, respectively. The fortuitously close agreement between the plane-wave result of this previous study and experiment was probably due to the use of a largecore pseudopotential for zinc. Von Oertzen et al (2005) found that, of the methods they examined, the PBE functional gave the best results for the structure of sphalerite. This included the hybrid B3LYP functional, which was found to overestimate the unit cell parameter by $2 \%$. Thus the choice of the PBE functional in the present work is justified.

Troilite is the stoichiometric form of iron sulphide with a structure based on that of distorted nickel arsenide with the space group P-62c. There are 24 atoms in the unit cell, where the Fe atoms are antiferromagnetically ordered along the $c$ axis. The antiferromagnetic interactions were explicitly included in order to obtain the correct cell parameters and $c / a$ ratio. Simulation of the structure using a non-magnetic approach leads to large errors in cell volume, as discussed by Wells et al. (2005). The calculated and experimental cell parameters of both sphalerite and troilite are compared in Table 1. 
Sphalerite is a wide gap semiconductor with measured direct band gap of $3.72 \mathrm{eV}$ (Tran et al 1997), whereas troilite has a very narrow experimental gap of $\sim 0.04 \mathrm{eV}$ (Gosselin et al 1976). The calculated band gap for sphalerite in the present work is $2.65 \mathrm{eV}$. However, it is well known that DFT underestimates band gaps as a result of the self-interaction error within the Kohn-Sham states (Perdew and Zunger 1981). Another property of interest for sphalerite is the charge distribution. While the Mulliken charge analysis for $\mathrm{ZnS}$ yields a low degree of ionicity, with charges of \pm 0.21 a.u., this is often misleading due to the sensitivity of this method of partitioning to the basis set details. A more reliable guide is the Born effective charge tensor for each atom, which is related to the polarization response and therefore not influenced by partition of the density matrix (a full discussion of different charge partitions can be found elsewhere (Ghosez et al 1998)). For sphalerite, these tensors are diagonal matrices with all three elements being equal due to the site symmetry of the special positions occupied within the cubic space group. The unique diagonal element is computed to be very close to the formal ionic charge at \pm 2.025 a.u..

As a further validation of the bulk calculation we have computed the vibrational spectrum for sphalerite. This was performed for the $2 \times 2 \times 2$ supercell used for the subsequent defect calculations and thus the resulting spectrum is the sum of the modes from 8 special points within the Brillouin zone of the conventional cell. The optic modes are found to span the range $245-317 \mathrm{~cm}^{-1}$, as compared to $277-350$ $\mathrm{cm}^{-1}$ experimentally (Vagelatos et al 1974). Both the observed systematic underestimation of the optic and acoustic modes is consistent with the overestimation of the unit cell volume by $3 \%$. The range of optic modes was found to be $263-313$ $\mathrm{cm}^{-1}$ in a previous study by Engel and Needs (1990), though here the calculations 
were performed at the LDA level and therefore yielded a considerably shorter lattice parameter of $5.186 \AA$.

Turning now to consider the defect chemistry of sphalerite, in pure $\mathrm{ZnS}$ it is likely that the intrinsic defect chemistry will favor ZnS Schottky over Frenkel defects due to the absence of sites to incorporate excess interstitial ions. Cation vacancies are also possible as an intrinsic defect mechanism and this possibility will be considered later in the context of Fe incorporation. The formation energy of the ZnS Schottky in the present supercell is given by:

$$
32(Z n S) \Rightarrow\left(Z n_{31} S_{31}\right)+Z n S
$$

Previous calculations employing interatomic potentials showed a strong preference for the binding of vacancies in sphalerite and gave a bound Schottky formation energy of $2.81 \mathrm{eV}$ (Wright and Gale 2004). In this work, we obtained a bound Schottky energy of $2.70 \mathrm{eV}$, in good agreement with the value obtained from the previous study. Indeed, all other factors being equal, it would be expected that the GGA result would be slightly lower due to the tendency to systematically underestimate the binding, as reflected in the slightly larger cell volume. Both theoretical methods indicate that intrinsic defect populations will be extremely low and that most zinc and sulphur vacancies will be produced as a result of extrinsic processes.

\subsection{Energetics of Iron Incorporation}

Calculations were carried out on supercells with different concentrations of impurities reflecting iron concentrations of up to $12.5 \mathrm{~mol} \% \mathrm{FeS}$. Table 2 gives the calculated total energies for each of the defective supercell configurations, as well as those of the 
pure sphalerite and troilite systems used to compute the solution energies reported in Table 3.

Substitution of a single $\mathrm{Zn}$ by $\mathrm{Fe}$ in an otherwise perfect lattice is described by Reaction 1 (Table 3) and has a calculated value of $+51 \mathrm{kJmol}^{-1}$. In our $2 \times 2 \times 2$ supercell this equates to an iron concentration of $3.25 \mathrm{~mol} \% \mathrm{FeS}$ where periodic $\mathrm{Fe}$ images are separated by $11.03 \AA$ and can be considered non-interacting. Increasing the size of the supercell to 128 atoms, and hence the Fe-Fe distance, made a difference of less than $1 \mathrm{kJmol}^{-1}$ to the incorporation energy. To examine the possibility of $\mathrm{Fe}$ pair formation at this low concentration, $2 \mathrm{Fe}$ ions were placed at adjacent $\mathrm{Zn}$ sites in the 128 -atom cell. The results give a binding energy of $10 \mathrm{kJmol}^{-}$ ${ }^{1}$, showing a moderate driving force towards the formation of Fe-S-Fe complexes at this concentration. Calculations using pair potentials (Wright 2009) did not show any binding energy on creation of Fe-Fe pairs, which can be attributed to the inability of the potential model to simulate complex Fe-Fe interactions. The change in zero point energy between a 64 atom cell containing one Fe atom and that containing two is less than $0.25 \mathrm{kJmol}^{-1}$ and thus correction for this contribution is negligible.

Placing $2 \mathrm{Fe}$ atoms in the stoichiometric $2 \times 2 \times 2$ cell is equivalent to a concentration of $6.25 \mathrm{~mol} \% \mathrm{FeS}$, where the two Fe atoms can be adjacent to each other (Figure 1c) or separated by, at most, $5.5 \AA$ (Figure 1d). The solution energies per Fe are almost identical at 46 and $48 \mathrm{kJmol}^{-1}$ for the bound and unbound configurations, respectively, and thus the pair formation energy is negligible. As additional Fe atoms are introduced in the cell, it becomes increasing difficult to avoid having one Fe inside the first shell of any other Fe and the solution energy continues to fall slightly until it reaches a minimum of $44.8 \mathrm{kJmol}^{-1}$ at $12.5 \% \mathrm{~mol} \% \mathrm{FeS}$. Our calculations do not show any driving force for the creation of larger clusters and at the highest 
concentration sampled, two pairs of $\mathrm{Fe}$ atoms separated by $5.5 \AA$ from each other (Figure $1 \mathrm{~h}$ ) have a slightly lower energy than a cluster of 4Fe impurities.

The energetics of iron incorporation are quite different when the reaction involves a non-stoichiometric phase. When Fe is placed at a $\mathrm{Zn}$ site adjacent to a $\mathrm{Zn}$ vacancy, the solution reaction energy, as described by reaction 5 in Table 3, is exothermic, with a value of $-53.5 \mathrm{kJmol}^{-1}$. The vacancy-impurity pair has a large binding energy of 92.8 $\mathrm{kJmol}^{-1}$, indicating that such vacancies will always be driven towards the Fe impurity. Configurations containing 2,3 and 4 iron atoms are also more favourable when placed close to the zinc vacancy. However, the binding between iron atoms and the vacancy becomes less favourable as concentrations rise.

\subsection{Influence of Iron Incorporation on Structure}

The incorporation of Fe into the sphalerite lattice appears to have almost no effect on local lattice strains, presumably because of the similarity of the $\mathrm{Zn}$ and Fe ionic radii. For a single isolated $\mathrm{Fe}$, the increase in the cubic lattice parameter, $a$, is $+0.000448 \AA$ per mol\% FeS, which agrees well with the value of $+0.000456 \AA$ of Skinner (1961). However, the increase in cell parameter $a$ for a bound Fe pair is smaller than this $(+0.000096 \AA$ per $\mathrm{mol} \% \mathrm{FeS})$ due to interactions between adjacent $\mathrm{Fe}$ atoms.

In all the above cases, the calculated spin state of the iron is consistent with being high spin $\mathrm{Fe}^{2+}$, with a net magnetic moment corresponding to 4 unpaired electrons per Fe. Based on a Mulliken analysis, with all the caveats associated with this partitioning of the density matrix, $90 \%$ of the net spin is associated with Fe, while the remainder is distributed over the surrounding $\mathrm{S}$ atoms. When two $\mathrm{Fe}^{2+}$ ions are present, the spins of the ions couple ferromagnetically, regardless of whether they are on adjacent sites or separated. 
When $\mathrm{Zn}$ vacancies are present, the increase in cell parameter with $\mathrm{Fe}$ is much larger at +0.001056 per mol\% FeS for a single impurity. When bound iron pairs are present we again see a decrease in this value, but to $+0.000491 \AA$ per mole FeS, close to the value of Skinner (1961). The calculated spin state for the Fe is again interpreted as

high spin, but now with a $d^{5}$ configuration, consistent with $\mathrm{Fe}^{3+}$. These results thus suggest that changes in the sphalerite cell parameter are influenced by defect configuration and by the degree of sample non-stoichiometry in conjunction with Fe concentration.

The observation of non-linear increase in cell parameter was also seen in the calculation of Wright (2009), who also investigated incorporation of $\mathrm{Mn}$ and $\mathrm{Cd}$ in sphalerite. Of these three dopants, incorporated individually or as mixtures, only Fe was found to influence the cell parameter in this way.

\section{4 Vibrational Spectra for Fe-doped $\mathrm{ZnS}$}

Vibrational spectroscopy, based on both infra-red and Raman techniques, has been used to experimentally characterize the presence of Fe within the sphalerite structure (Pring et al 2008, Osadchii and Gorbaty 2010). Although several peaks may be identified, the interpretation and assignment of these modes is not unambiguous and therefore computational methods can potentially offer some insight.

In order to examine whether a vibrational signature exists, associated with the presence of $\mathrm{Fe}$ in different configurations within $\mathrm{ZnS}$, the vibrational spectra have been determined for three cases. Firstly, the phonons were computed for the undoped bulk $\mathrm{ZnS}$, and then subsequently for the material with one and two Fe impurities. For the case of two Fe atoms, the favoured configuration where they are on adjacent sites was chosen. In each case a 64-atom unit cell was chosen and the phonons were 
determined for the gamma point only, though we note that this corresponds to sampling $8 \mathrm{k}$-points for the conventional sphalerite structure.

For pure $\mathrm{ZnS}$, the maximum frequency observed is at $316.5 \mathrm{~cm}^{-1}$ associated with combinations of the $\mathrm{Zn}-\mathrm{S}$ stretching modes. When a single Fe atom is introduced then a new band appears at slightly higher frequency, $323-324 \mathrm{~cm}^{-1}$, due to three combinations of Fe-S stretching modes. For two Fe atoms on adjacent zinc sites, similar modes appear in the range $324-325 \mathrm{~cm}^{-1}$ and therefore would be difficult to distinguish from the single iron case. A new highest frequency mode appears at 327 $\mathrm{cm}^{-1}$ involving the antisymmetric stretching combination of the Fe-S bonds for the common sulphur atom, combined with a breathing of the tetrahedra. Distinct Fe-S-Fe bending modes are also observed at 281 and $285 \mathrm{~cm}^{-1}$.

Whilst there are several modes that have considerably larger eigenvector components for Fe than for $\mathrm{Zn}$, and therefore could be regarded as partially localized at the defect, the frequencies almost always overlap with bands of the pure $\mathrm{ZnS}$. Hence, given the broadening effects present, it is difficult to identify a clear discernable signature for the presence of iron at low concentrations, except perhaps the slight increase in the frequency maximum. Similarly, differentiation between paired and unpaired Fe substitutional defects proves to be challenging. It should be noted that the majority of experimental investigations involve samples with higher Fe concentrations than in the present phonon calculations, and therefore direct comparison is difficult. Furthermore, samples of sphalerite often contain traces of other elements, thus offering an additional complication.

Given that Raman spectroscopy tends to yield the best-resolved experimental bands for sphalerite samples, the breathing modes of the iron defects offer the best chance of a signature. For a single Fe substitution, there is a localized breathing of the Fe-S 
bonds at $278 \mathrm{~cm}^{-1}$ that is relatively decoupled from the vibrations of the $\mathrm{ZnS}$ structure. For an adjacent pair of Fe dopants, this mode appears to be shifted to lower frequency $\left(\sim 252 \mathrm{~cm}^{-1}\right)$ and becomes strongly coupled to the surrounding lattice. Hence, the identification of a particular frequency with this breathing must be considered tentative for this system. Based on this data, it is possible that a narrow Raman mode could be observed for well-separated Fe dopants, that broadens and red shifts on pairing. Experimental studies of Kharbish (2007) identified a clear correlation between the presence of Fe and a peak at $337 \mathrm{~cm}^{-1}$ in the Raman spectrum. However, this is assigned to the presence of $\mathrm{Fe}^{3+}$, rather than the isovalent substitution considered in the present work, and therefore the absence of this peak in our vibrational spectra is consistent with this interpretation. Osadchii and Gorbaty (2010) found a strong increase in Raman intensities with Fe content at 295 and $325 \mathrm{~cm}^{-1}$, and proposed the presence of a structural transition at $20 \% \mathrm{Fe}$ content associated with infinite $\mathrm{Fe}^{2+}$ clusters. In the present work we do not consider such high loadings of $\mathrm{Fe}$ and so cannot comment on the existence or otherwise of such clusters. While the experimental mode at $325 \mathrm{~cm}^{-1}$ could be tentatively assigned to the calculated mode at $327 \mathrm{~cm}^{-1}$, associated with a pair of $\mathrm{Fe}$ ions on adjacent sites, a detailed determination of the Raman intensities would be required to validate this. Unfortunately, the determination of accurate Raman intensities is more complex for solids than for infrared and so a more certain comparison of the spectra against experiment will have to be deferred to future work. 


\section{CONCLUSIONS}

The results of our calculations point to a number of significant findings concerning the atomic arrangement of $\mathrm{Fe}$ impurities within sphalerite. Firstly, $\mathrm{Fe}$ can be incorporated into sphalerite more easily when it is $\mathrm{Zn}$ deficient, i.e. at high sulphur fugacity. The difference in solution energies between the stoichiometric and $\mathrm{Zn}$ deficient cases is $93.5 \mathrm{~kJ} \mathrm{~mol}^{-1}$ at $3.125 \mathrm{~mol} \% \mathrm{FeS}$, and $65.8 \mathrm{~kJ} \mathrm{~mol}^{-1}$ at $12.5 \mathrm{~mol} \%$ FeS. In addition, reaction energies are exothermic when sphalerite is $\mathrm{Zn}$ deficient. Secondly, in stoichiometric sphalerite, the formation of Fe pairs is favoured at low Fe concentrations by $\sim 10 \mathrm{kJmol}^{-1}$, but as more $\mathrm{Fe}$ is introduced into the system, the driving force for pair formation decreases rapidly. This is most likely due to the distribution of other Fe ions in the vicinity. This would imply that a weak coupling between $\mathrm{Fe}$ ions exists, but only exerts a small driving force on Fe-Fe pair formation. However, no barrier exists to pair or larger cluster formation either. It would seem that changes in cell volume with increasing Fe are strongly dependent on the degree of clustering and non-stoichiometry. Finally, at low concentrations, the calculated phonons show only a small shift with the incorporation of $\mathrm{Fe}$ suggesting that vibrational spectroscopy may not be able to differentiate between the different configurations sampled.

Acknowledgements: The authors gratefully acknowledge the support of the Australian Research Council through the Discovery programme, as well as the provision of computing resources by iVEC and NCI. 


\section{References}

Balabin A.I. and Urusov V.S. (1995) Recalibration of the sphalerite cosmobarometer - experimental and theoretical treatment. Geochim. Cosmochim. Acta 59, 1401-410.

Balabin A.I. and Sack R.O. (2000) Thermodynamics of (ZnFe)S sphalerite. A CVM approach with large basis clusters. Mineral. Mag. 64, 923-943.

Barton P.B. and Toulmin P. III. (1966) Phase relations involving sphalerite in the FeZn-S System. Economic Geol. 61, 815-849.

Bernadini G.P., Borgheresi M., Cipriani C., Di Benedetto F., and Romanelli M. (2004) Mn distribution in in sphalerite an EPR study. Phys. Chem. Miner. 31, 80-84.

Cao L., Huang S. and E S. (2004) ZnS/CdS/ZnS quantum dot quantum well produced in inverted micelles. J. Colloid Interface Sci. 273, 478-482.

Cook N.J., Ciobanu C.L., Pring A., Skinner W., Shimizu M., Danyushevsky L., SainiEidukat B., and Melcher F. (2009) Trace and minor elements in sphalerite: A LAICPMS study. Geochim. Cosmochim. Acta, 73, 4761-4791.

Di Benedetto F., Bernadini G.P., Costagliola P., Plant D., and Vaughan D.J. (2005a) Compositional zoning in sphalerite crystals. Am. Miner. 90, $1384-1392$.

Di Benedetto F., Andreozzi G.B., Bernadini G.P., Borgheresi M., Caneschi A., Cipciani C., Gatteschi D., and Romanelli M. (2005b) Short range order of $\mathrm{Fe}^{2+}$ impurities, isolated and in pairs, in $\mathrm{ZnS}$ and $\mathrm{CdS}$ studies by the Mossbauer effect. Phys. Chem. Miner. 32, $339-348$.

Engel G.E., and Needs R.J. (1990) Calculations of the structural properties of cubic zinc sulfide. Phys. Rev. B 41, 7876-7878.

Ghosez Ph, Michenaud J.-P. and Gonze X. (1998) Dynamical atomic charges: The case of $\mathrm{ABO}_{3}$ compounds. Phys. Rev. B 58, 6224-6240. 
Gosselin J.R., Townsend M.G., and Tremblay R.J. (1976) Electric anomalies at the phase transition of FeS. Solid State Comm. 19, 799-803.

Junquera J., Paz O., Sánchez-Portal D., and Artacho E. (2001) Numerical atomic orbitals for linear-scaling calculations. Phys. Rev. B, 64, 235111.

Kharbish S. (2007) A Raman spectroscopic investigation of Fe-rich sphalerite: effect of fe-substitution. Phys. Chem. Miner. 34, 551-558.

King H.E., and Prewitt C.T. (1982) High-pressure and high-temperature polymorphism of iron sulphide (FeS). Acta. Cryst. B 38,1877-1887.

Lepetit P., Bente K., Doering T., and Luckhaus S. (2003) Crystal chemistry of Fecontaining sphalerites. Phys. Chem. Miner, 30, 185-191.

Louie S.G., Froyen S., and Cohen M.L. (1982) Nonlinear ionic pseudopotentials in spin-density-functional calculations. Phys. Rev. B 26, 1738-1742.

Moreno J., and Soler J.M. (1992) Optimal meshes for integrals in real- and reciprocalspace unit cells. Phys. Rev. B 45, 13891-13898.

Osadchii E.G., and Gorbaty Y.E. (2010) Raman spectra and unit cell parameters of sphalerite solid solutions $\left(\mathrm{Fe}_{\mathrm{x}} \mathrm{Zn}_{1-\mathrm{x}} \mathrm{S}\right)$. Geochim. Cosmochim. Acta 74, 568-573.

Pattrick R.A.D., Mosselmans J.F.W., and Charnock J.M. (1998) An X-ray absorption study of doped sphalerites. Eu. J. Mineral. 10, 239-249.

Perdew J.P., Burke K., and Ernzerhof M. (1996) Generalized Gradient Approximation made simple. Phys. Rev. Letters, 77, 3865-3868.

Perdew J.P., and Zunger A. (1981) Self-interaction correction to density-functional approximations for many-electron systems. Phys. Rev. B 23, 5048-5079.

Pring A., Tarantino S.C., Tenailleau C., Etschmann B., Carpenter M.A., Zhang M., Liu, Y. and Withers R.L. (2008) The crystal chemistry of Fe-bearing sphalerites: An infrared spectroscopic study. Am. Mineral. 93, 591-597. 
Scott S.D. and Barnes H.L. (1971) Sphalerite geothermometry and geobarometry. Economic Geol. 66, 653-669.

Skinner W. (1961) Unit-cell edges of natural and synthetic sphalerite. Am. Mineral. 46, 1399-1411.

Soler J.M., Artacho E., Gale J.D., García A., Junquera J., Ordejón P., and SánchezPortal D. (2002) The SIESTA method for ab initio order-N materials simulation. $J$. Phys.: Condens. Matter 14, 2745-2779.

Toulmin P., Barton P.B., and Wiggins L.B. (1991) Commentary on the sphalerite geobarometer. Am. Mineral. 76, 1038-1051.

Tran T.K., Park W., Tong W., Kyi M.M., Wagnar B.K., and Summers C.J. (1997) Photoluminescence properties of ZnS epilayers. J. Appl. Phys. 81, 2803-2809.

Troullier N., and Martins J.L. (1991) Efficient pseudopotentials for plane-wave calculations. Phys. Rev. B 43, 1993-2006.

Vagelatos N., Wehe D. and King J.S. (1974) Phonon dispersion and phonon densities of states for ZnS and ZnTe. J. Chem. Phys. 60, 3613-3618.

Von Oertzen G.U., Jones R.T. and Gerson A.R. (2005) Electronic and optical properties of $\mathrm{Fe}, \mathrm{Zn}$ and $\mathrm{Pb}$ sulfides. Phys. Chem. Miner. 32, 255-268.

Wells S., Alfe D., Blanchard L., Brodholt J., Calleja M., Catlow R., Proce D., Tyler R,. and Wright, K (2005) Ab initio simulations of magnetic iron sulphides. Mol. Sim. 31, 379-384.

Withers R.L., Welberry T.R. Pring A., Tenailleau C., and Liu Y. (2005) 'Soft' phonon modes, structured diffuse scattering and the crystal chemistry of Fe-bearing sphalerites. J. Solid State Chem. 178, 655-660. 
Wright K., and Gale J.D. (2004) Interatomic potentials for the simulation of the zincblende and wurtzite forms of $\mathrm{ZnS}$ and CdS: Bulk structure, properties and phase stability. Phys. Rev. B 70, article number 035211.

Wright K. (2009) The incorporation of cadmium, manganese and ferrous iron in sphalerite: Insights from computer simulation. Can. Miner. 47,615-623. 
Table 1. Comparison of the calculated and experimental structures for pure sphalerite and troilite. Expermental structure for sphalerite from Skinner (1961) and for troilite from King and Prewitt (1982).

\begin{tabular}{lll}
\hline Parameter & Calculated & Experiment \\
\hline Sphalerite & & \\
a $(\AA)$ & 5.458 & 5.405 \\
Vol. $\left(\AA^{3}\right)$ & 162.66 & 157.93 \\
Troilite & & \\
a $(\AA)$ & 5.97 & 5.96 \\
c $(\AA)$ & 11.74 & 11.75 \\
c/a & 1.966 & 1.971 \\
Vol. $\left(\AA^{3}\right)$ & 361.97 & 361.95 \\
& & \\
\hline
\end{tabular}


Table 2. Computed energies used in reactions $1-7$.

Configurations relate to Figures 1 and 2.

\begin{tabular}{ccc}
\hline Composition & Energy (eV) & Configuration \\
\hline $\mathrm{Zn}_{32} \mathrm{~S}_{32}$ & -73012.0874 & $1 \mathrm{a}$ \\
$\mathrm{Fe} \mathrm{Zn}_{31} \mathrm{~S}_{32}$ & -73422.0198 & $1 \mathrm{~b}$ \\
$\mathrm{Fe}_{2} \mathrm{Zn}_{30} \mathrm{~S}_{32}$ & -73832.0576 & $1 \mathrm{c}$ \\
$\mathrm{Fe}_{2} \mathrm{Zn}_{30} \mathrm{~S}_{32}$ & -73832.0209 & $1 \mathrm{~d}$ \\
$\mathrm{Fe}_{3} \mathrm{Zn}_{29} \mathrm{~S}_{32}$ & -74242.0577 & $1 \mathrm{e}$ \\
$\mathrm{Fe}_{3} \mathrm{Zn}_{29} \mathrm{~S}_{32}$ & -74242.0485 & $1 \mathrm{f}$ \\
$\mathrm{Fe}_{4} \mathrm{Zn}_{28} \mathrm{~S}_{32}$ & -74652.0526 & $1 \mathrm{~g}$ \\
$\mathrm{Fe}_{4} \mathrm{Zn}_{28} \mathrm{~S}_{32}$ & -74652.0769 & $1 \mathrm{~h}$ \\
$\mathrm{Zn}_{31} \mathrm{~S}_{32}$ & -71005.4574 & $2 \mathrm{a}$ \\
$\mathrm{FeZn}_{30} \mathrm{~S}_{32}$ & -71416.3522 & $2 \mathrm{~b}$ \\
$\mathrm{Fe}_{2} \mathrm{Zn}_{29} \mathrm{~S}_{32}$ & -71827.0522 & $2 \mathrm{c}$ \\
$\mathrm{Fe}_{2} \mathrm{Zn}_{29} \mathrm{~S}_{32}$ & -71827.5563 & $2 \mathrm{~d}$ \\
$\mathrm{Fe}_{3} \mathrm{Zn}_{28} \mathrm{~S}_{32}$ & -72237.8261 & $2 \mathrm{e}$ \\
$\mathrm{Fe}_{3} \mathrm{Zn}_{28} \mathrm{~S}_{32}$ & -72237.4040 & $2 \mathrm{f}$ \\
$\mathrm{Fe}_{4} \mathrm{Zn}_{27} \mathrm{~S}_{32}$ & -72648.1746 & $2 \mathrm{~g}$ \\
$\mathrm{Fe}_{4} \mathrm{Zn}_{27} \mathrm{~S}_{32}$ & -72647.5272 & $2 \mathrm{~h}$ \\
$\mathrm{Energy}(\mathrm{eV})$ & per formula unit & \\
$\mathrm{FeS}(\mathrm{troilite})_{2} \mathrm{ZnS}-2692.0844$ & \\
\hline
\end{tabular}


Table 3. Calculated solution reaction energies $\left(\mathrm{kJmol}^{-1}\right)$ per Fe.

\begin{tabular}{|c|c|c|c|}
\hline & Reaction - no Zn vacancy & $\% \mathrm{FeS}$ & $\begin{array}{c}\text { Energy per } \\
\text { FeS }\end{array}$ \\
\hline 1 & $32(Z n S)+F e S \Rightarrow\left(F e Z n_{31} S_{32}\right)+Z n S$ & 3.125 & 51.0 \\
\hline 2 & $32(Z n S)+2 F e S \Rightarrow\left(F e_{2} Z n_{30} S_{32}\right)+2 Z n S$ & 6.25 & 45.9 \\
\hline 3 & $32(Z n S)+3 F e S \Rightarrow\left(F_{3} Z_{n} n_{29} S_{32}\right)+3 Z n S$ & 9.375 & 45.5 \\
\hline 4 & $32(\mathrm{ZnS})+4 \mathrm{FeS} \Rightarrow\left(\mathrm{Fe}_{4} \mathrm{Zn}_{28} \mathrm{~S}_{32}\right)+4 \mathrm{ZnS}$ & 12.5 & 44.8 \\
\hline \multicolumn{4}{|c|}{ Reaction - with $\mathrm{Zn}$ vacancy } \\
\hline 5 & $31(Z n S)+F e S \Rightarrow\left(F e Z n_{30} S_{32}\right)+Z n S$ & 3.25 & -53.3 \\
\hline 6 & $31(\mathrm{ZnS})+2 \mathrm{FeS} \Rightarrow\left(\mathrm{Fe}_{2} \mathrm{Zn}_{29} \mathrm{~S}_{32}\right)+2 \mathrm{ZnS}$ & 6.25 & -56.7 \\
\hline 7 & $31(\mathrm{ZnS})+3 \mathrm{FeS} \Rightarrow\left(\mathrm{Fe}_{3} \mathrm{Zn}_{28} \mathrm{~S}_{32}\right)+3 \mathrm{ZnS}$ & 9.375 & -31.6 \\
\hline 8 & $31(\mathrm{ZnS})+4 \mathrm{FeS} \Rightarrow\left(\mathrm{Fe}_{4} \mathrm{Zn}_{27} \mathrm{~S}_{32}\right)+4 \mathrm{ZnS}$ & 12.5 & -21.03 \\
\hline
\end{tabular}


Figure 1. Distribution patterns of Fe substitution in stoichiometric sphalerite.

\begin{tabular}{|c|c|c|c|}
\hline (a) & (b) & (c) & (d) \\
\hline $\begin{array}{l}\mathrm{Zn} \mathrm{Zn} \mathrm{Zn} \mathrm{Zn} \\
S \mathrm{~S} S \mathrm{~S}\end{array}$ & $\begin{array}{l}\mathrm{Zn} \mathrm{Zn} \mathrm{Zn} \mathrm{Zn} \\
S \quad S \quad S \quad S\end{array}$ & $\begin{array}{l}\mathrm{Zn} \mathrm{Zn} \mathrm{Zn} \mathrm{Zn} \\
\mathrm{S} S \mathrm{~S} S\end{array}$ & $\begin{array}{l}\mathrm{Zn} \mathrm{Zn} \mathrm{Zn} \mathrm{Zn} \\
S \mathrm{~S} S \mathrm{~S}\end{array}$ \\
\hline $\mathrm{Zn} \mathrm{Zn} \mathrm{Zn} \mathrm{Zn}$ & $\mathrm{Zn} \mathrm{Zn} \mathrm{Zn} \mathrm{Zn}$ & $\mathrm{Zn} \mathrm{Zn} \mathrm{Zn} \mathrm{Zn}$ & $\mathrm{Zn} \mathrm{Zn} F \mathrm{Fen}$ \\
\hline $\begin{array}{llll}S & S & S & S\end{array}$ & $\begin{array}{llll}S & S & S\end{array}$ & $S \quad S \quad S \quad S$ & $S \quad S \quad S$ \\
\hline $\mathrm{Zn} \mathrm{Zn} \mathrm{Zn} \mathrm{Zn}$ & $\mathrm{Zn} \mathrm{Zn} \mathrm{Fe} Z \mathrm{Zn}$ & \begin{tabular}{l|l|l|l}
$\mathrm{Zn}$ & $\mathrm{Fe}$ & $\mathrm{Fe}$ & $\mathrm{Zn}$
\end{tabular} & $\mathrm{Zn} \mathrm{Zn} \mathrm{Zn} \mathrm{Zn}$ \\
\hline $\begin{array}{llll}S & S & S & S\end{array}$ & $S \quad S \quad S \quad S$ & $\begin{array}{llll}S & S & S & S\end{array}$ & $S \mathrm{~S} S$ \\
\hline $\mathrm{Zn} \mathrm{Zn} \mathrm{Zn} \mathrm{Zn}$ & Zn Zn Zn Zn & $\mathrm{Zn} \mathrm{Zn} \mathrm{Zn} \mathrm{Zn}$ & $\mathrm{Zn} \mathrm{Zn}$ Fe $\mathrm{Zn}$ \\
\hline$S \quad S \quad S \quad S$ & $S \quad S \quad S \quad S$ & $\begin{array}{ll}S & s\end{array}$ & $S S S$ \\
\hline (e) & $(f)$ & (g) & (h) \\
\hline $\mathrm{Zn} \mathrm{Zn} \mathrm{Zn} \mathrm{Zn}$ & $\mathrm{Zn} \mathrm{Zn}$ Fe $\mathrm{Zn}$ & $\mathrm{Zn} \mathrm{Zn} \mathrm{Zn} \mathrm{Zn}$ & $\mathrm{Zn}$ Fe $\mathrm{Fe}$ Zn \\
\hline $\begin{array}{llll}S & S & S & S\end{array}$ & $S \quad S \quad S \quad S$ & $S \quad S \quad S \quad S$ & $\begin{array}{llll}S & S & S\end{array}$ \\
\hline $\mathrm{Zn} \mathrm{Zn} \mathrm{Zn} \mathrm{Zn}$ & $\mathrm{Zn} \mathrm{Zn} \mathrm{Zn} \mathrm{Zn}$ & $\mathrm{Zn} \mathrm{Zn} \mathrm{Zn} \mathrm{Zn}$ & $\mathrm{Zn} \mathrm{Zn} \mathrm{Zn} \mathrm{Zn}$ \\
\hline $\begin{array}{llll}S & S & S & S\end{array}$ & $\begin{array}{llll}S & S & S & S\end{array}$ & $\begin{array}{llll}S & S & S & S\end{array}$ & $S \quad S \quad S \quad S$ \\
\hline $\mathrm{Zn} \mathrm{Zn} \mathrm{Zn} \mathrm{Zn}$ & $\mathrm{Zn} \mathrm{Zn} \mathrm{Zn} \mathrm{Zn}$ & $\mathrm{Fe} \mathrm{Fe} \mathrm{Fe} \mathrm{Fe}$ & $\mathrm{Zn}$ Fe $\mathrm{Fe} \mathrm{Zn}$ \\
\hline $\begin{array}{llll}S & S & S & S\end{array}$ & $S \quad S \quad S \quad S$ & $\begin{array}{llll}S & S & S & S\end{array}$ & $\begin{array}{llll}S & S & S & S\end{array}$ \\
\hline $\mathrm{Fe} \mathrm{Fe} \mathrm{Fe} \mathrm{Zn}$ & $\begin{array}{lll}\mathrm{Zn} & \mathrm{Fe} & \mathrm{Fe} \\
\mathrm{Zn}\end{array}$ & $\mathrm{Zn} \mathrm{Zn} \mathrm{Zn} \mathrm{Zn}$ & $\mathrm{Zn} \mathrm{Zn} \mathrm{Zn} \mathrm{Zn}$ \\
\hline S S & $\mathrm{S}$ & $S \mathrm{~S}$ & $S \quad S$ \\
\hline
\end{tabular}


Figure 2. Distribution patterns of Fe substitution in non-stoichiometric sphalerite where $\mathrm{V}$ denotes a $\mathrm{Zn}$ vacancy.

\begin{tabular}{|c|c|c|c|}
\hline (a) & (b) & (c) & (d) \\
\hline $\mathrm{Zn} \mathrm{Zn} \mathrm{Zn} \mathrm{Zn}$ & $\mathrm{Zn} \mathrm{Zn} \mathrm{Zn} \mathrm{Zn}$ & $\mathrm{Zn} Z n \mathrm{Zn} Z n$ & $\mathrm{Zn} \mathrm{Zn} \mathrm{Zn} \mathrm{Zn}$ \\
\hline $\begin{array}{llll}S & S & S & S\end{array}$ & $\begin{array}{llll}S & S & S & S\end{array}$ & $\begin{array}{llll}S & S & S & S\end{array}$ & $\begin{array}{llll}S & S & S & S\end{array}$ \\
\hline $\mathrm{Zn} Z \mathrm{Zn} \mathrm{Zn}$ & $\mathrm{Zn} \vee \mathrm{Fe} \mathrm{Zn}$ & $\mathrm{Zn} \mathrm{Zn} \mathrm{V} \mathrm{Zn}$ & $\mathrm{Zn} \mathrm{Zn} \mathrm{Zn} \mathrm{Zn}$ \\
\hline $\begin{array}{llll}S & S & S & S\end{array}$ & $\begin{array}{llll}S & S & S & S\end{array}$ & $S \mathrm{~S}$ & $S \quad S \quad S$ \\
\hline $\mathrm{Zn} \mathrm{Zn} \mathrm{Zn} \mathrm{Zn}$ & $\mathrm{Zn} Z \mathrm{Zn} \mathrm{Zn} \mathrm{Zn}$ & $\mathrm{Zn} \mathrm{Zn} \mathrm{Zn} \mathrm{Zn}$ & $\mathrm{Zn} Z n \vee Z n$ \\
\hline$S \quad S$ & $S$ & $S \mathrm{~s}$ & $S \mathrm{~s}$ \\
\hline $\mathrm{Zn} \mathrm{Zn} \mathrm{Zn} \mathrm{Zn}$ & $\mathrm{Zn} \mathrm{Zn} \mathrm{Zn} \mathrm{Zn}$ & $\mathrm{Zn} \mid \mathrm{Fe} \mathrm{Fe} / \mathrm{Zn}$ & $\mathrm{Zn}$ Fe $\mathrm{Fe} / \mathrm{Zn}$ \\
\hline$S \quad S \quad S \quad S$ & $S \quad S$ & $S \mathrm{~S}$ & $S \mathrm{~S}$ \\
\hline (e) & $(f)$ & (g) & (h) \\
\hline $\mathrm{Zn} \mathrm{Zn}$ & $\mathrm{Zn} \mathrm{Zn} \mathrm{Zn} \mathrm{Zn}$ & $\mathrm{Zn} \mathrm{Zn} \mid \mathrm{Fe} F e$ & $\mathrm{Zn} \mathrm{Zn} \mathrm{Zn} \mathrm{Zn}$ \\
\hline $\begin{array}{llll}S & S & S & S\end{array}$ & $S \quad S \quad S$ & $S \quad S \quad S \quad S$ & $\begin{array}{llll}S & S & S & S\end{array}$ \\
\hline $\mathrm{Zn} \mathrm{Zn} \mathrm{Zn} \mathrm{Zn}$ & $\mathrm{Zn} Z \mathrm{Zn} \vee \mathrm{Zn}$ & $\mathrm{Zn} \mathrm{Zn} \mid \mathrm{V} \mathrm{Zn}$ & $\mathrm{Zn} \mathrm{Zn} \vee \mathrm{Zn}$ \\
\hline$S \mathrm{~S} S$ & $\begin{array}{llll}S & S & S & S\end{array}$ & $S S S$ & $S \quad S \quad S$ \\
\hline $\mathrm{Zn} \vee \mathrm{Zn} \mathrm{Zn}$ & $\mathrm{Zn} \mathrm{Zn} \mathrm{Zn} \mathrm{Zn}$ & \begin{tabular}{l|l}
$\mathrm{Zn}$ & $\mathrm{Fe}$ \\
$\mathrm{Fe}$ & $\mathrm{Zn}$
\end{tabular} & $\mathrm{Zn} \mathrm{Zn} \mathrm{Zn} \mathrm{Zn}$ \\
\hline $\begin{array}{llll}S & S & S & S\end{array}$ & $S \quad S \quad S \quad S$ & $\begin{array}{llll}S & S & S & S\end{array}$ & $\begin{array}{llll}S & S & S & S\end{array}$ \\
\hline $\mathrm{Fe} F \mathrm{Fe} \mathrm{Zn}$ & \begin{tabular}{l|l}
$\mathrm{Zn}$ & $\mathrm{Fe} F \mathrm{Fe}$
\end{tabular} & $\mathrm{Zn} \mathrm{Zn} \mathrm{Zn} \mathrm{Zn}$ & $\mathrm{Fe} \mathrm{Fe} \mathrm{Fe} \mathrm{Fe}$ \\
\hline$S \quad S \quad S$ & $\begin{array}{llll}S & S & S & S\end{array}$ & $\begin{array}{llll}S & S & S & S\end{array}$ & $S \quad S \quad S$ \\
\hline
\end{tabular}

